\title{
As imagens dos livros didáticos de ciências para os anos iniciais do ensino fundamental e as visões de saúde que veiculam ${ }^{1}$
}

\author{
Lucia Helena Pralon²
}

\begin{abstract}
Resumo
Este trabalho teve como objetivo analisar a visualidade dos livros didáticos de ciências destinados aos anos iniciais do ensino fundamental, com foco no conjunto das imagens fotográficas referentes à saúde. Apesar da crescente qualidade de sua diagramação e ilustração, o papel pedagógico de suas imagens ainda não é valorizado nos processos educativos. A investigação, ancorada por referenciais dos estudos das linguagens e da semiótica, revelou que mais de $30 \%$ da área de impressão das páginas é ocupada por imagens, com predomínio das imagens fotográficas sobre os demais tipos. A análise do conjunto de fotografias referentes à saúde indicou a predominância do foco sobre as ações individuais que promovem saúde e bem-estar, caracterizando uma ênfase Comportamental de Educação em Saúde.
\end{abstract}

Palavras-chave: Livro Didático de Ciências; Imagem de Saúde; Anos Iniciais do Ensino Fundamental.

The initial years of elementary school science textbooks images and its health visions

\section{Abstract:}

This work aimed to analyze the visuality of science textbooks for the early years of elementary school, focusing on the set of photographic images related to health. Despite the increasing quality of its diagramming and illustration, the pedagogical role of its images is not yet valued in the educational processes. The research, anchored by references from language studies and semiotics, revealed that over $30 \%$ of the page printing area is occupied by images, with the predominance of photographic images over other types. The analysis of the set of photographs related to health indicated the predominance of focus on individual actions that promote health and well-being, characterizing a Behavioral emphasis on Health Education.

Keywords: Science Textbook; Health's Image; Initial Years of Elementary School.

\section{Introdução}

Tradicionalmente, as questões referentes à saúde humana têm sido abordadas nas disciplinas Ciências, no ensino fundamental e Biologia, no ensino médio, e os livros didáticos dessas disciplinas trazem conteúdos sobre o tema. Considerando que o livro didático ainda se constitui no mais importante material impresso que circula no universo discursivo escolar, onde exerce inegável influencia na formação intelectual dos alunos e na prática dos professores

\footnotetext{
1 Esta pesquisa foi realizada com apoio do Programa Observatório da Educação, da Coordenação de Aperfeiçoamento de Pessoal de Nível Superior - CAPES/Brasil e da Fundação Carlos Chagas Filho de Amparo à Pesquisa do Estado do Rio de Janeiro - FAPERJ

2 Escola de Educação / Programa de Pós-graduação em Educação - PPGEdu, Universidade Federal do Estado do Rio de Janeiro (UNIRIO), Rio de Janeiro, RJ, Brasil. e-mail: luciapralon2@yahoo.com.br.
} 
(CHOPPIN, 2004; GOUVÊA, MARTINS, IZQUIERDO, 2006; MARTINS, 2012; NETO, FRACALANZA, 2003), torna-se fundamental compreender de qual saúde eles falam e sob quais perspectivas de responsabilidade e autonomia, na abordagem dos processos de saúde e doença, dialogam seus textos e imagens. No Brasil, a distribuição do livro didático é garantida pelo Ministério da Educação através do Programa Nacional Livro Didático - PNLD, que avalia previamente a qualidade dos livros que serão encaminhados às escolas, incentivando a produção de materiais cada vez mais adequados às necessidades da educação pública brasileira e às suas diretrizes e orientações. Podemos considerar que, nos últimos vinte anos, a criação de critérios de avaliação para a seleção das obras adquiridas e distribuídas colaborou de modo significativo para que os livros didáticos em geral, e os de ciências em particular, tivessem um salto qualitativo em muitos de seus aspectos constitutivos (NETO; FRACALANZA, 2003).

Um desses aspectos, que aqui queremos destacar, diz respeito ao projeto gráfico desses livros. Para André Villas Boas (2007), o projeto de design gráfico é um conjunto de elementos visuais, que se constitui tanto de elementos textuais como não textuais (ilustrações, fotos e grafismos) reunidos numa determinada área preponderantemente bidimensional e que resulta exatamente da relação entre esses elementos. Nas páginas dos livros didáticos as diferentes linguagens (verbal, matemática e imagética) se mesclam em sua diagramação, através de textos verbais, esquemas, desenhos, gravuras, fotografias, mapas, gráficos e tabelas, tornando o ato de leitura desses materiais uma tarefa nada simples para os estudantes. Nesse sentido o livro didático atual pode ser considerado como um texto híbrido semiótico (MARTINS, 2007), na medida em que se utiliza de diferentes modos semióticos de representação e interpretação culturalmente construídos. Para Gouvêa, Martins e Izquierdo (2006) o aspecto gráfico, nos livros didáticos, é recurso de retórica, pois as estruturas que o compõem orientam caminhos de leitura que são construídos pela intencionalidade do autor, se constituindo em uma narrativa que exerce influência sobre a escolha do livro pelo professor e sobre a aprendizagem dos estudantes.

As mudanças percebidas na visualidade dos livros de Ciências também se devem à evolução ocorrida nos processos de produção, reprodução, distribuição e recepção de imagens, que tem proporcionado um aumento significativo tanto na quantidade quanto na qualidade das mesmas. Em estudo anterior (PRALON, 2011) constatamos, em uma coleção didática de Ciências destinada aos anos finais do Ensino Fundamental, que cerca de $40 \%$ da superfície de suas páginas 
(área de impressão) era ocupada por imagens dos mais diferentes tipos. Mais recentemente voltamos nossa atenção para as coleções didáticas destinadas aos anos iniciais do Ensino Fundamental. Este trabalho teve como objetivo analisar a visualidade dos livros didáticos de ciências destinados aos anos iniciais do ensino fundamental, com foco no conjunto das imagens fotográficas referentes à saúde. Apresentamos os resultados da análise da visualidade de seis coleções didáticas de Ciências destinadas aos anos iniciais do ensino fundamental, aprovadas pelo PNLD 2013, buscando compreender as concepções de saúde que veiculam. Nossa hipótese, baseada na premissa de que os textos visuais são capazes de comunicar do mesmo modo que os textos verbais, é que os possíveis sentidos atribuídos as imagens presentes nesses materiais podem se relacionar com aspectos característicos de determinada visão de saúde.

\section{Leitura de Imagens}

O fato de os livros didáticos terem se tornado mais ilustrados torna relevante um maior entendimento do papel que as imagens desempenham tanto no processo de ensino e aprendizagem dos conteúdos de ciências quanto na formação identitária dos alunos. Afinal, aquilo que pode ser expresso na linguagem verbal por meio da escolha entre diferentes classes de palavras e estruturas semânticas, é, na comunicação visual, expresso através da escolha, por exemplo, dos diferentes usos de cores ou de diferentes estruturas composicionais (KRESS; VAN LEEUWEN, 1996). Essas estruturas realizam sentidos assim como as estruturas linguísticas o fazem. Do mesmo modo que não basta saber ler a palavra para dar sentido a um texto, também nas representações visuais os sentidos possíveis ultrapassam a simples identificação visual de seus componentes.

Imagens são discursos e, como tal, possuem uma orientação dialógica. Adotando uma pespectiva baktiniana de linguagem admitimos que dialogia diz respeito às diversas maneiras como duas ou mais vozes entram em contato em um discurso. A orientação dialógica de um discurso é algo natural, ele sempre se encontra com o discurso do outro na medida em que precisa se orientar para o conhecido, para o "já dito" (BAKHTIN, 2002), sem o que se tornaria incompreensível. No ato compreensivo os discursos imagéticos, em semelhança com os discursos verbais, se constituem do encontro de outros discursos já conhecidos. Orientam-se, 
portanto para um terreno conhecido e compartilhado entre o produtor e o leitor da imagem. 0 texto imagético, em semelhança com o texto verbal, é um enunciado polifônico que contém e revela as vozes do seu tempo. Daí a importância da contextualização dos discursos no seu tempo, afinal "estudar o discurso em si mesmo, ignorar a sua orientação externa, é algo tão absurdo como estudar o sofrimento psíquico fora da realidade a que está dirigido e pela qual ele é determinado" (BAKHTIN, 2002, p.99).

Optamos por uma visão de linguagem frente à perspectiva social, cuja preocupação reside na relação entre linguagem e sociedade. Entendemos que os textos (verbais, imagéticos, sonoros, gestuais etc.) são portadores de discursos que produzem efeitos sociais na medida em que refletem e refratam seus valores. Desse modo, ao tomarmos as imagens como textos, reconhecemos que elas não são transparentes e tampouco transmitem um único sentido. Essa natureza polissêmica das imagens cria a necessidade de um aprendizado para sua leitura.

\section{O conceito de saúde}

O modo como se conceitua saúde num determinado momento histórico determina o papel do indivíduo em relação à sua própria saúde e gera diferentes abordagens no campo educacional.

Em trabalho que analisa as ações educativas em saúde para escolares a partir dos anais dos eventos relevantes de Saúde, Oliveira (1996) identificou, no Brasil, duas concepções básicas de educação em saúde: a concepção de Educação Sanitária e a concepção de Educação em Saúde.

A Educação Sanitária "representava o caminho da disciplina higiênica e da moral sadia e os profissionais de saúde, em especial os médicos sanitaristas, detinham o poder de decisão nas questões de saúde, dentre elas as dirigidas aos escolares" (OLIVEIRA, 1996, p.10), predominou do século XIX até meados do século XX e caracterizou três momentos históricos distintos das ações em saúde: um período higienista-eugenista (1889-1929) onde as ações de caráter eugenista objetivavam erradicar o germe, a doença, a pobreza e a ignorância para a construção de uma nação saudável, para a constituição da raça brasileira; um período sanitarista (19301950 ) inserido numa proposta de modernização da sociedade, no qual o indivíduo era visto como 
responsável pela sua saúde e ao Estado cabia promover ampla divulgação dos princípios de saúde para que o indivíduo rompesse com sua ignorância; e um período de retrocesso da educação sanitária (década de 1960) onde, apesar da percepção de que fatores sociais e ecológicos funcionariam como determinantes da saúde, o esvaziamento das práticas sanitárias, não consideradas como prioritárias nas políticas de gastos do governo, representou uma volta a década de 1920.

A concepção de Educação em Saúde surge após a década de 1970 num novo momento histórico para o país, quando as questões sociais ganham relevância no debate do processo saúde/doença. De acordo com a autora "a ampliação do conceito de saúde ampliava a visão dos profissionais de saúde e estimulava uma nova postura - a postura educativa - devendo ser contribuição marcante no avanço das ações de atenção primária em saúde" (OLIVEIRA, 1996, p.80). Paralelamente, no campo educacional a Lei no 5692/71 (BRASIL, 1971) torna obrigatório o ensino de saúde na escola básica. A escola, nesse contexto, era entendida como potencial aliada e espaço favorável para o desenvolvimento de ações educativas em saúde.

A partir do início da década de 1980, a ideia de promoção da saúde começa a se relacionar mais com autonomia e emancipação do que com as abordagens higienistas e normativas típicas das medidas preventivas primárias. A atual perspectiva de promoção da saúde, defendida tanto pelo campo da saúde quanto pelo educacional, pode ser percebida como uma abordagem socioambiental. De acordo com classificação de Marcia Westphal (2006), a abordagem socioambiental se diferencia das abordagens biomédica e comportamental, entre outros aspectos, por entender saúde como um estado positivo de bem-estar biopsicossocial e espiritual, de realização de aspirações e atendimento de necessidades onde os determinantes de saúde incluem as condições de risco biológicas, psicológicas, socioeconômicas, educacionais, culturais, políticas e ambientais.

Considerando que a escola, além de sua função pedagógica, tem uma inegável função social e política, ela deve estar comprometida com a formação crítica dos alunos, de modo que a abordagem dos temas de saúde ganhe outros objetivos além do aprendizado de conteúdos específicos e da incorporação de hábitos saudáveis, como o reconhecimento dos seus deveres e direitos sociais (moradia, saneamento, transporte, serviço de saúde etc.) e as formas de exigi-lo. Rompendo, desse modo, com enfoques deterministas que ora atribuem a condição de saúde do 
indivíduo à sua realidade social ora ao poder público ou, de modo inverso, colocam todo o peso no indivíduo, na sua herança genética e no empenho pessoal.

A Educação em Saúde nas escolas brasileiras de ensino fundamental tem sido, até então, garantida por leis de diferentes níveis, como a Lei de Diretrizes e Bases da Educação de 1996 (LDB), o Plano Nacional de Educação de 2001 (PNE) e as Diretrizes Curriculares Nacionais de 1998 (DCN), e também por normas legais como os Parâmetros Curriculares Nacionais de 1996 (PCN) e o Programa Saúde na Escola (PSE) de 2007 que, apesar de não serem leis, têm grande importância por influenciar a educação em nível nacional. Uma análise das orientações contidas nesses documentos revela que, apesar de seus diferentes níveis de ação, eles estão expressamente comprometidos com uma perspectiva de Educação em Saúde baseada em um conceito de saúde ampliado, "considerado como um estado positivo e dinâmico de busca de bem-estar, que integra os aspectos físico e mental (ausência de doença), ambiental (ajustamento ao ambiente), pessoal/emocional (auto realização pessoal e afetiva) e sócio ecológico (comprometimento com a igualdade social e com a preservação da natureza)" (SHALL; STRUCHINER, 1999, p.S4). Como consequência, espera-se que a educação (incluindo aqui também os materiais produzidos para fins pedagógicos) esteja comprometida com essa perspectiva e estabeleça ações voltadas tanto para o indivíduo aluno quanto para o aluno integrante de uma comunidade, que o capacitem para a melhoria da sua qualidade de vida e saúde, e também para uma maior participação no controle desse processo.

\section{Imagens nos livros didáticos}

Os procedimentos metodológicos da pesquisa incluíram a seleção dos livros e a definição dos critérios de análise. Selecionamos para análise as seis coleções de ciências mais escolhidas nacionalmente pelos professores para efetivo uso em sala de aula no triênio 2013/2014/2015. De acordo com dados disponibilizados publicamente no Portal do Fundo Nacional de Desenvolvimento da Educação - FNDE, foram distribuídos em todo o Brasil 10.400.420 (dez milhões quatrocentos mil e quatrocentos e vinte) livros de 23 (vinte e três) diferentes coleções didáticas de Ciências. Sendo que as seis coleções mais distribuídas no país (Quadro 1), juntas, representaram mais da metade da quantidade total de livros, ou seja, 7.463 .220 (sete milhões 
quatrocentos e sessenta e três mil e duzentos e vinte), o que representa $72 \%$ dos exemplares distribuídos (BRASIL-FNDE, 2015).

Quadro 1: Coleções de Ciências mais distribuídas pelo Programa Nacional do Livro Didático - PNLD 2013

\begin{tabular}{|c|c|c|c|c|}
\hline & COLEÇÃO & AUTORES & EDITORA & TOTAL \\
\hline A & $\begin{array}{l}\text { Porta Aberta } \\
\text { Ciências }\end{array}$ & Ângela Gil Sueli Fanizzi & Editora FTD & 1.975 .139 \\
\hline B & $\begin{array}{c}\text { Projeto Buriti - } \\
\text { Ciências }\end{array}$ & Lia Monguilhott Bezerra & Editora Moderna & 1.736 .919 \\
\hline C & $\begin{array}{c}\text { A Escola é Nossa } \\
\text { Ciências }\end{array}$ & $\begin{array}{c}\text { Karina Alessandra Pessôa da Silva } \\
\text { Leonel Delvai Favalli }\end{array}$ & Editora Scipione & 1.245 .879 \\
\hline D & Ápis Ciências & $\begin{array}{c}\text { Maria Cristina da Cunha Campos } \\
\text { Rogério Gonçalves Nigro }\end{array}$ & Editora Ática & 1.221 .137 \\
\hline $\mathrm{E}$ & $\begin{array}{l}\text { Aprender Juntos } \\
\text { Ciências }\end{array}$ & Cristiane Motta & Edições SM & 761.853 \\
\hline $\mathrm{F}$ & Projeto Prosa & Maíra Rosa Carnevalle & $\begin{array}{c}\text { Saraiva Livreiros } \\
\text { Editores }\end{array}$ & 522.293 \\
\hline \multicolumn{4}{|c|}{ TOTAL DE LIVROS DAS SEIS COLEÇÕES DISTRIBUÍDOS } & 7.463 .220 \\
\hline
\end{tabular}

Fonte: Elaborado pela autora

A análise dos conteúdos dos livros foi desenvolvida em duas etapas: exploração do material com levantamento da visualidade dos livros e análise do conjunto das imagens fotográficas de saúde.

\section{A visualidade dos livros didáticos}

Nessa primeira etapa da investigação foram analisados os 30 livros que compõem as seis coleções selecionadas (livros do primeiro ao quinto anos do ensino fundamental), sob os seguintes aspectos: área ocupada pelas imagens, número de imagens e tipos de imagens encontradas. Quanto ao projeto gráfico as seis coleções analisadas não fogem da forma de apresentação típica dos livros didáticos atuais com capa, contracapa, folha de rosto, apresentação, índice e desenvolvimento de um conteúdo específico que está hierarquicamente organizado em capítulos, de forma que devem ser lidos preferencialmente na ordem de apresentação (GOUVÊA; MARTINS; IZQUIERDO, 2006). 


\section{HSE H ORIZONTES}

A contagem das imagens presentes em qualquer material sempre depende do critério adotado para definir o que é uma imagem. Algumas vezes um conjunto de fotos ou desenhos mostrando sucessão de fatos ou fenômenos pode ser considerado por alguns autores como uma única imagem composta, enquanto que por outros como várias imagens que guardam relação entre si. Nesse estudo estamos considerando a unidade somente quando o conjunto apresenta uma única legenda, isto é, qualquer texto verbal ligado diretamente à imagem, ou quando há elementos gráficos de ligação como setas ou traços. Quando cada ilustração apresenta um texto a ela vinculado individualmente, e não há uma legenda para o conjunto, cada imagem foi considerada individualmente.

A medição do espaço ocupado pelas imagens nas páginas dos livros foi feita de modo artesanal. A estratégia utilizada foi a criação de uma "máscara" que pudesse fornecer rapidamente uma informação visual, minimamente confiável, da área ocupada pelas imagens na superfície da página. Utilizando um acetato transparente, do mesmo tamanho da página do livro e dividido em 100 quadrantes, sobreposto sobre a página do livro, procedíamos à contagem do número de quadrantes ocupados por imagens; definindo desse modo um percentual bastante aproximado de ocupação da página pelas imagens.

Através da contagem das imagens e da medição do seu tamanho constatamos que mais de $30 \%$ da área de impressão das páginas é ocupada por imagens, e que, em média, são encontradas três imagens por página (Tabela 1).

Tabela 1: Área ocupada por imagens nas coleções - PNLD 2013

\begin{tabular}{c|c|c|c|c}
\hline Coleção & $\begin{array}{c}\text { Área } \\
\text { ocupada }\end{array}$ & $\begin{array}{c}\text { Número de } \\
\text { páginas }\end{array}$ & $\begin{array}{c}\text { Quantidade de } \\
\text { imagens }\end{array}$ & $\begin{array}{c}\text { Imagens por } \\
\text { página }\end{array}$ \\
\hline A & $24,5 \%$ & 1039 & 2863 & 2,8 \\
\hline B & $30,2 \%$ & 856 & 2115 & 2,5 \\
\hline C & $26,9 \%$ & 987 & 2599 & 2,6 \\
\hline D & $46,9 \%$ & 1113 & 3179 & 2,9 \\
\hline E & $27,2 \%$ & 754 & 2578 & 3,4 \\
\hline F & $31,1 \%$ & 748 & 2031 & 2,7 \\
\hline
\end{tabular}

Fonte: Elaborado pela autora. 
Quanto aos tipos de imagens encontradas, as fotografias (Tabela 2), os desenhos e as sinalizações foram os mais frequentes nas coleções, representando $97 \%$ do total de imagens, com predomínio das imagens fotográficas sobre os demais tipos.

Tabela 2: Tipos de imagens encontradas nas coleções

\begin{tabular}{|c|c|c|c|c|c|c|c|}
\hline \multirow{2}{*}{ TIPO DE IMAGEM } & \multicolumn{6}{|c|}{ COLEÇÃO } & \multirow{2}{*}{$\begin{array}{c}\text { Total de imagens } \\
\text { de cada tipo }\end{array}$} \\
\hline & A & B & C & D & $E$ & $\mathbf{F}$ & \\
\hline Fotografia & 1.143 & 545 & 1.260 & 1.354 & 1.172 & 804 & $6.278 \quad(41,1 \%)$ \\
\hline Desenho & 979 & 965 & 912 & 707 & 1.086 & 548 & $(34,0 \%)$ \\
\hline Montagem & 12 & 41 & 3 & 80 & 11 & 61 & $(1,4 \%)$ \\
\hline Gráfico & 11 & 3 & 7 & 10 & 10 & 19 & $(0,4 \%)$ \\
\hline Mapa & 9 & 0 & 4 & 2 & 16 & 4 & $(0,2 \%)$ \\
\hline Tabela & 79 & 12 & 12 & 15 & 8 & 51 & $(1,2 \%)$ \\
\hline Sinalização & 630 & 549 & 318 & 1.011 & 275 & 544 & $(21,7 \%)$ \\
\hline Total & 2.863 & 2.115 & 2.516 & 3.179 & 2.578 & 2.031 & Total geral 15.282 \\
\hline
\end{tabular}

Fonte: Elaborado pela autora.

Ao analisar os livros, nos deparamos com um número grande de imagens que, apesar de não se relacionarem diretamente com os conteúdos abordados, direcionam e desempenham uma importante função conduzindo e determinando as ações do aluno no uso do material. Essas imagens foram por nós classificadas como sendo imagens do tipo 'sinalizações'; apesar de serem chamadas de ícones pelos autores de duas coleções.

\section{As imagens fotográficas de saúde}

Chamamos de imagens de saúde aquelas que, de algum modo, remetem a aspectos relativos à saúde, quer por seus elementos icônicos, quer pela referência direta a questões de saúde no texto verbal circundante com termos como: saúde, doença, enfermidade, qualidade de vida, medicina(I), medicamentos, fitoterápicos e outros. Isto significa dizer que estar ou não relacionada à saúde é também uma decorrência do contexto onde a imagem ocorre.

Diante da alta prevalência das imagens fotográficas nos livros podemos pensar sobre o significado que isso pode ter para o ensino de ciências se considerarmos a ilusão de realidade que elas provocam. No convívio social é comum admitir que uma fotografia represente com 
eficácia a realidade visível, ou seja, que aquilo que vemos em uma foto de fato tenha existido e estado ali em algum momento exatamente como se vê. Esse realismo atribuído à imagem fotográfica é fruto de uma construção ideológica respaldada pela gênese tecnológica do procedimento fotográfico, conforme nos alertam Filho e Moraes $(2019, \mathrm{p} .86)$.

De onde vêm essas crenças? A gênese tecnológica do procedimento fotográfico é um dos argumentos que as sustentam: como projeção de uma cena de forma global em uma superfície fotossensível de forma mecânica e automática produziria análogos confiáveis do real e, por isso, considerada não objeto de intervenções.

Ainda que consideremos as modernas câmeras digitais e os softwares que são capazes de manipular as imagens sem deixar pistas, a fotografia parece manter, de certo modo, esse compromisso com a realidade. Exemplo disso é o fato de um documento com nossa fotografia ainda ser garantia de identidade em muitas instâncias sociais. Sendo assim, podemos considerar que a fotografia presente em materiais didáticos carrega consigo esse caráter de verdade, onde “interage peculiarmente como o texto verbal, restituindo a 'realidade' que as palavras só podem sugerir" (VOLLI, 2007, p.280), desse modo contribuindo para naturalizar ideias, conceitos, princípios, comportamentos, estéticas etc.

Contudo, é preciso considerar que a fotografia é testemunho de uma realidade determinada pelas convenções e opções culturais historicamente realizadas. Nesse sentido admitimos que a fotografia não só informa como também conforma uma determinada visão de mundo. $\mathrm{O}$ ato fotográfico indiscutivelmente marca uma materialidade passada, mas também representa uma escolha num conjunto de escolhas possíveis, que tem relação direta com a visão de mundo do fotógrafo, que definiu o objeto a ser fotografado, o ângulo, o enquadre, a iluminação etc., ou do diagramador de um livro que escolheu a foto para ser inserida naquele contexto específico.

A análise das imagens fotográficas de saúde envolveu dois processos distintos: categorização do tipo de fotografia e da ênfase em saúde percebida na imagem e no texto de referência no livro.

Quanto ao tipo, as fotografias foram classificadas como 'imagem científica', 'cena do cotidiano' ou como 'informativas' (Quadro 2). 
Quadro 2 - Imagens fotográficas de saúde

\begin{tabular}{|c|c|c|c|}
\hline Tipo de fotografia de saúde & Subtipo & № de & grafias \\
\hline \multirow{6}{*}{ IMAGEM CIENTIÍFICA } & Imagem de Microscopia & 23 & \multirow{6}{*}{55} \\
\hline & Raio X & 10 & \\
\hline & Tomografia & 1 & \\
\hline & Endoscopia & 1 & \\
\hline & Ultrassom & 3 & \\
\hline & Ampliação didática & 17 & \\
\hline \multirow{4}{*}{ CENA DO COTIDIANO } & Foco em seres humanos & 334 & \multirow{4}{*}{564} \\
\hline & Foco em animais & 13 & \\
\hline & Foco em objetos & 129 & \\
\hline & Foco em ambientes & 88 & \\
\hline \multirow{3}{*}{ INFORMATIVA } & Cartazes de saúde & 10 & \multirow{3}{*}{12} \\
\hline & Documentos de saúde & 1 & \\
\hline & Instalações artísticas & 1 & \\
\hline Total & \multicolumn{3}{|r|}{631} \\
\hline
\end{tabular}

O conceito de imagem científica é bastante complexo. Martine Joly (1996) considera que são imagens que ajudam a observar e interpretar os diversos fenômenos e que podem ser produzidas a partir do registro de fenômenos físicos, permitindo uma observação mais ou menos direta e mais ou menos sofisticada da realidade. Desse modo consideramos como imagens científicas aquelas obtidas através de instrumentos técnicos como microscópios, telescópios, aparelhos de raio $\mathrm{X}$, tomógrafos, ultrassom etc. Essas imagens, que a rigor não poderiam ser chamadas de fotografias por serem produzidas por outros meios, estão aqui incluídas devido ao fato de serem imagens técnicas. As imagens técnicas diferem das imagens artesanais por seu modo de produção. Desse modo, diferentemente das imagens artesanais, como os desenhos, pinturas e esculturas, cuja produção depende basicamente da habilidade do autor e cuja reprodução é mais difícil, as imagens técnicas dependem menos das habilidades físicas do seu autor e ainda podem ser amplamente reproduzidas. Em semelhança com as fotografias estas imagens são vistas por muitos como uma cópia fiel da realidade, de maneira que "o expectador acredita, não que o que ele vê é real, mas, que o que vê existiu, ou pôde existir no real" (AUMONT, 1993, p.111).

Quanto aos demais tipos de fotografias, as classificadas como cenas do cotidiano são aquelas que retratam pessoas, animais, ambientes ou objetos nas mais variadas situações, as 
informativas reproduzem cartazes, qualquer material impresso contendo informações sobre saúde, ou qualquer tipo de objeto artístico.

Cerca de $90 \%$ das imagens fotográficas referentes à saúde encontradas, são cenas do cotidiano. A presença marcante desse tipo de imagem que, em última análise, retrata a realidade ou "uma" realidade escolhida, como vimos anteriormente, configura o representado como algo familiar e aceitável, ou seja, naturalizado. E, como consequência, provoca o apagamento de outras realidades não representadas.

Em relação aos temas, conteúdos disciplinares do ensino de Ciências, os mais recorrentes nos contextos das imagens de saúde foram os referentes às questões de ambiente e saúde, e à alimentação saudável seguidos pelos temas relacionados ao estímulo de hábitos saudáveis, ao conhecimento da anatomia e fisiologia do corpo humano e ao estudo das doenças.

Quanto à ênfase em saúde percebida nas imagens, adotamos a classificação já utilizada em trabalho anterior SOUZA (2014), baseada na proposta de Marcia Westphal (2006), onde consideramos a existência de três distintas concepções de Educação em Saúde que se definem pela ocorrência de características típicas de uma determinada abordagem de Promoção da Saúde: Educação em Saúde com abordagem Biomédica, Educação em Saúde com abordagem Comportamental ou Educação em Saúde com abordagem Socioambiental; de acordo com o conceito de saúde que norteia o discurso pedagógico, os determinantes considerados e as estratégias propostas. Desse modo, trouxemos esses conceitos para nossa análise (Quadro 3), procurando identificar nas fotografias aspectos que pudessem estar direcionando seu foco para uma ênfase Biomédica, quando o foco estava nas questões biológicas e fisiológicas; para uma ênfase Comportamental, quando o foco estivesse nas ações individuais que promovem saúde e bem estar; e para uma ênfase Socioambiental, quando o foco fosse os determinantes de saúde que geram condições de risco.

A Figura 1 traz o exemplo de uma fotografia de saúde classificada como imagem científica e do tipo Raio $X$ onde, de acordo com nossos parâmetros teórico/analíticos, os elementos icônicos presentes evidenciam aspectos da fisiologia do corpo humano, caracterizando uma ênfase Biomédica em sua abordagem de saúde. 


\section{USF HORIZONTES}

Figura 1: Imagem fotográfica de saúde com ênfase Biomédica.

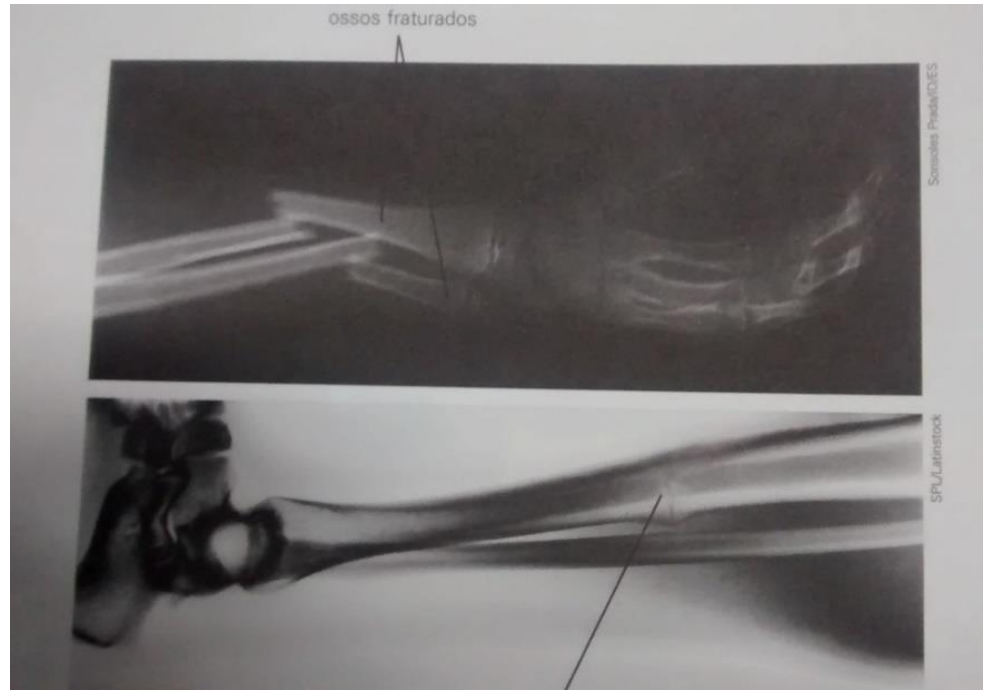

Fonte: Cristiane Motta. Aprender Juntos Ciências (Livro 4). Edições SM, 2011, p.46.

A Figura 2 é uma imagem fotográfica de saúde classificada como cena do cotidiano onde os elementos icônicos evidenciam a presença de lixo espalhado em ambiente público, gerando condições de risco, caracterizando uma ênfase Socioambiental na abordagem de saúde, com foco predominante, nos determinantes socioeconômicos.

Figura 2: Imagem fotográfica de saúde com ênfase Socioambiental

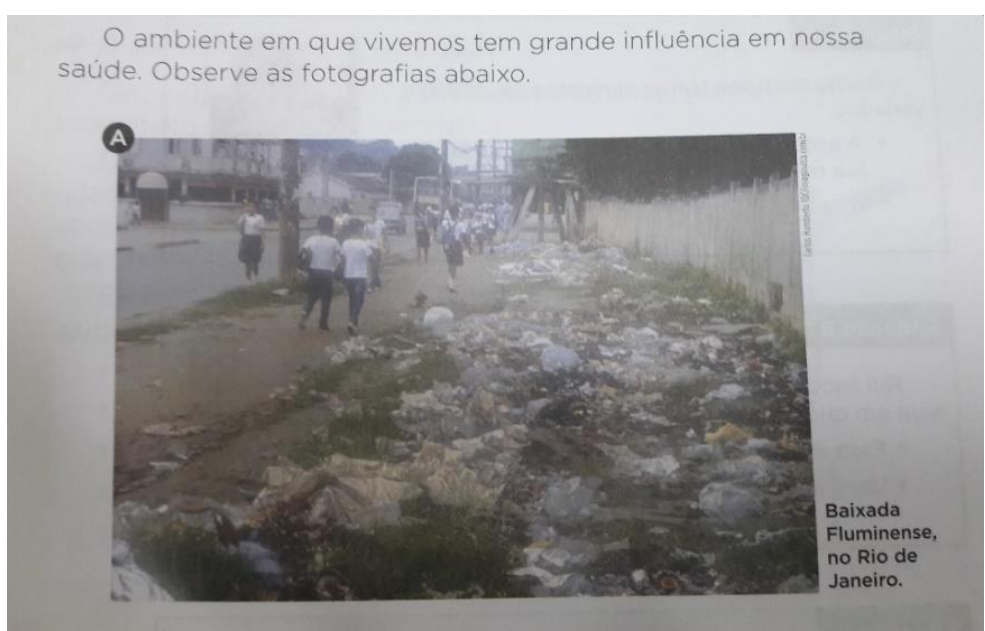

Fonte: SILVA, K.A.P; FAVALLI, L.D. A Escola é Nossa (livro 3), Scipione, 2011, p.152.

Já a Figura 3, que também é uma imagem fotográfica de saúde do tipo cenas do cotidiano, é composta por 4 fotografias onde o elemento iconográfico principal é o ser humano em ações 


\section{HSE}

típicas de cuidados com o asseio pessoal e com os alimentos, caracterizando uma ênfase em saúde Comportamental com foco nos hábitos de higiene.

Figura 3: Imagem fotográfica de saúde com ênfase Comportamental.

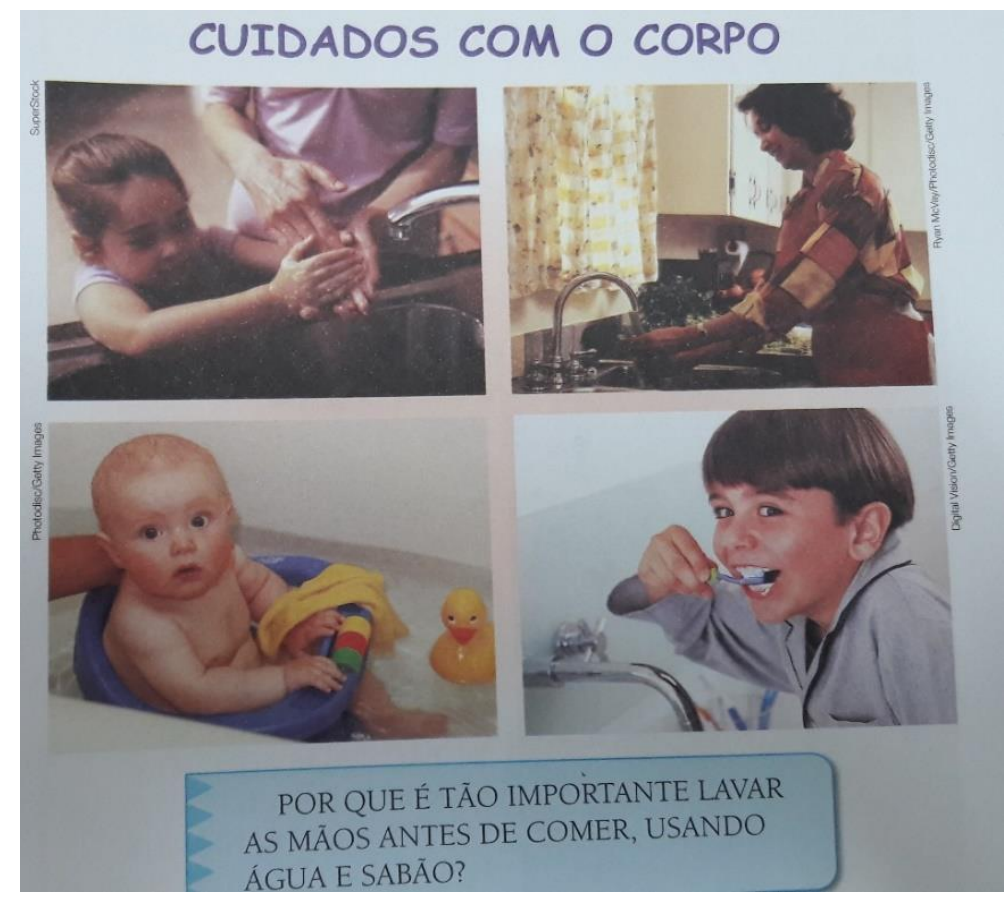

Fonte: GIL, A.; FANIZZI, S. Porta Aberta (livro 1), Editora FTD, 2011, p.23.

O quadro 3 sintetiza o resultado da classificação das imagens fotográficas de saúde de acordo com a ênfase em saúde percebida e seu principal foco. Nota-se um evidente predomínio de imagem com ênfase Comportamental evidenciando, principalmente, os aspectos relativos ao estilo de vida das pessoas. Em relação às imagens com ênfase Biomédica, não houve um predomínio significativo de foco. Já nas fotografias com ênfase Sócio Ambiental, destacamos o elevado número de imagens fotográficas com foco nos determinantes ambientais de saúde.

Quadro 3 - Ênfase em saúde percebida nas fotografias

\begin{tabular}{|l|l|l|l|}
\hline Ênfase em saúde na foto & Foco & \multicolumn{2}{|l|}{ No de imagens } \\
\hline \multirow{4}{*}{ BIOMÉDICA } & nos agentes causadores de doenças & 63 & \multirow{3}{*}{163} \\
\cline { 2 - 4 } & nas estratégias de diagnóstico e cura & 70 & \\
\cline { 2 - 4 } & na fisiologia do corpo & 30 & \\
\hline \multirow{3}{*}{ COMPORTAMENTAL } & nos hábitos de higiene & 52 & \multirow{3}{*}{343} \\
\cline { 2 - 4 } & no estilo de vida & 270 & \\
\cline { 2 - 4 } & Na relação com o ambiente & 21 & \\
\hline
\end{tabular}

Periódico Horizontes - USF - Itatiba, SP - Brasil - e019042 


\begin{tabular}{|l|l|l|}
\hline & Nos determinantes biológicas & 3 \\
\cline { 2 - 3 } & Nos determinantes psicológicos & 0 \\
\cline { 2 - 3 } & Nos determinantes socioeconômicos & 17 \\
\cline { 2 - 3 } & Nos determinantes educacionais & 6 \\
\cline { 2 - 3 } & Nos determinantes culturais & 5 \\
\cline { 2 - 3 } & Nos determinantes políticos & 3 \\
\cline { 2 - 3 } & Nos determinantes ambientais & 91 \\
\hline
\end{tabular}

Fonte: Elaborado pela autora.

Em relação ao predomínio das fotografias com ênfase Comportamental, essas imagens, como enunciados polifônicos que são, contem e revelam as vozes do seu tempo; tempo esse onde o estímulo à adoção de práticas saudáveis, como praticar atividades físicas e adotar alimentação mais natural, nos bombardeiam por todos os lados nas mais diferentes mídias. Sobre a influência das mídias em nosso modo de viver a pesquisadora Mônica Fantin alerta que “as mídias não só asseguram formas de socialização e transmissão simbólica, mas também participam como elementos importantes da nossa prática sociocultural na construção de significados da nossa inteligibilidade do mundo" (FANTIN, 2007, p.2).

Corroboram essa afirmação os resultados encontrados em trabalho anterior (PRALON e GOUVEA, 2015) onde foram analisadas as justificativas dadas por estudantes de um curso de graduação em Pedagogia para o fato de se considerarem ou não pessoas saudáveis. As duas categorias mais frequentes foram: ter hábitos alimentares saudáveis e praticar atividades físicas. Os argumentos usados pelos alunos se referiam quase que unicamente às suas escolhas individuais, sem referência a outros aspectos sociais (econômicos, políticos, culturais) que seriam capazes de viabilizar o acesso a uma alimentação de qualidade e à prática de atividade física, caracterizando essas duas variáveis determinantes de saúde apenas como ações de responsabilidade individual.

\section{Conclusões}

Apesar do baixo valor dado pelos professores ao papel pedagógico das imagens nos materiais pedagógicos verificamos que nos livros didáticos estas disputam território com o texto 
escrito, ocupando mais de 30\%, em média, da área de impressão das páginas, com predomínio das imagens fotográficas sobre os demais tipos.

Considerando que as fotografias, por sua capacidade de representar a realidade, muitas vezes são tomadas como "verdades", o fato de cerca de $90 \%$ delas representarem cenas do cotidiano, nos leva a refletir sobre qual cotidiano representam. A exposição dos estudantes a algumas cenas, e não outras, contribui para a naturalização de ideias, comportamentos, estéticas e outros valores ali representados e desnaturalização de outros. Como vimos, a análise do conjunto de fotografias referentes à saúde revelou a predominância do foco sobre as ações individuais que promovem saúde e bem-estar, caracterizando uma ênfase Comportamental na abordagem dos temas de saúde. O encontrado contraria as orientações contidas nos documentos oficiais que, de acordo com o que percebemos em nossa análise, estão expressamente comprometidas com uma perspectiva de Educação em Saúde baseada em um conceito de saúde ampliado, onde os diferentes determinantes sociais dos processos de saúde e doença são considerados e as ações são voltadas tanto para o indivíduo aluno como para o cidadão aluno.

Essa constatação leva-nos a questionar o conteúdo do discurso imagético nos livros didáticos e a propor um maior investimento em ações voltadas para o desenvolvimento de um aprendizado intencional para a leitura de imagens que, de modo geral, apresentam um importante potencial pedagógico capaz de mobilizar e potencializar a compreensão dos conhecimentos científicos, além de exercerem forte influência sobre a formação cidadã.

\section{Referências}

AUMONT, J. A imagem . Trad. de Estela S. Abreu e Claudio C. Santoro. Campinas: Papirus, 1993.

BAKHTIN, M. M. Questões de literatura e estética: a teoria do romance. São Paulo: Editora Hucitec, 2002.

BRASIL. FNDE. PNLD 2013 - Coleções mais distribuídas por componente curricular. Disponível em: http://www.fnde.gov.br/programas/livro-didatico/livro-didatico. Acesso em: 24 fev. 2015. 
BRASIL. Ministério da Educação e Cultura. Lei no 5.692, de 11 de agosto de 1971. Fixa diretrizes e bases para o ensino de 1ำ e 2을 graus, e dá outras providências. Diário Oficial da República Federativa do Brasil, Brasília, DF, 12 ago. 1971. Seção 1.

CHOPPIN, A. História dos livros e das edições didáticas: sobre o estado da arte. Educação e Pesquisa, set./dez. 2004, vol.30, n.3, p.549-566. ISSN 1517-9702.

FANTIN, M. Alfabetização midiática na escola. In. VII Seminário "Mídia, Educação e Leitura" do 16 COLE. Campinas, 2007.

FILHO, O. G. R.; MORAES, I. F. A encenação na fotografia: montando cenas e contando histórias. Galaxia, São Paulo, n.40, jan.-abr., 2019, ISSN 1982-2553.

GOUVÊA, G; MARTINS, I.; IZQUIERDO, M. Discutindo as retóricas do texto didático de Física a partir de uma análise do seu projeto gráfico. In: X ENCONTRO DE PESQUISA EM ENSINO DE FíSICA, 10, 2006, Londrina, Atas [...], Londrina, 2006, p.1-12.

JOLY, M. Introdução à análise da imagem. Trad. de Marina Appenzeller. Campinas: Papirus, 1996.

KRESS, G.; VAN LEEUWEN, T. Reading images: the grammar of visual design. London: Routledge. 1996.

MARTINS, I. Quando o objeto de investigação é o texto: uma discussão sobre as contribuições da análise crítica do discurso e da análise Multimodal como referenciais para a pesquisa sobre livros didáticos de ciências. In: NARDI, R (Org.) A pesquisa em ensino de Ciências no Brasil: alguns recortes. São Paulo: Escrituras, 2007, p.95-116.

MARTINS, I. Analisando livros didáticos na perspectiva dos estudos do discurso: compartilhando reflexões e sugerindo uma agenda para a pesquisa. In: O livro didático de Ciências: contextos de exigência, critérios de seleção, práticas de leitura e uso em sala de aula / [Editoras] Isabel Martins, Guaracira Gouvêa e Rita Vilanova. - Rio de Janeiro : :[s.n.], 2012.

NETO, J. M.; FRACALANZA, H. O livro didático de ciências: problemas e soluções. Ciência \& Educação, v.9, n.2, p.147-157, 2003.

OLIVEIRA, N. S. M. Ações educativas em saúde para escolares à luz de conferências e congressos nacionais de saúde. Campo Grande, MS: 1996. 186f. Dissertação (Mestrado em Saúde Coletiva) - Universidade Federal do Mato Grosso do Sul, 1996.

PRALON, L. H. As imagens da saúde em livros didáticos de ciências. Rio de Janeiro, 2011. $146 f$. Tese (Doutorado em Educação e Saúde) - Núcleo de Tecnologia Educacional para a Saúde, Universidade Federal do Rio de Janeiro, Rio de Janeiro, 2011. 
PRALON, L.H.; GOUVÊA, G. Uma análise das concepções dos estudantes sobre os determinantes de saúde. In: FARIAS, I. M. S. F et al. (Orgs.) Didática e a prática de ensino na relação com a formação de professores. Fortaleza: EdUECE, 2015, p. 6555-6566. (recurso digital).

SHALL, V. T.; STRUCHINER, M. Educação em saúde: novas perspectivas. Cad. Saúde Pública, 1999, vol.15, suppl.2, p.S4-S6. ISSN 0102-311X.

SOUZA, L. H. P. Imagens científicas e ensino de ciências: uma experiência docente de construção de representação simbólica a partir do referente real. Cadernos CEDES (Impresso), v. 34, p. 127-131, 2014.

VILLAS-BOAS, A. O que é [e o que nunca foi] design gráfico. 6. ed. Rio de Janeiro: 2AB, 2007.

VOLLI, U. Manual de semiótica. Trad. de Silva Debetto C. Reis. São Paulo: Edições Loyola, 2007.

WESTPHAL, M. F. Promoção da saúde e prevenção de doenças. In: Campos, G.W.S. et al. (Orgs). Tratado de saúde coletiva. São Paulo: Hucitec/Fiocruz: Rio de Janeiro, 2006, p. 635-667.

Recebido em setembro de 2018.

Aprovado em maio de 2019. 